\title{
Tensões e conflitos entre vida e trabalho no capitalismo contemporâneo
}

Tensions and conflicts between life and work on contemporary capitalism

Resumo O artigo questiona a possibilidade de libertação da subjetividade no campo de tensão entre vida e trabalho que constitui a qualificação profissional. Para tanto, analisa as aproximações entre formação e trabalho, em direção à consciência de si e à consciência social, no âmbito da cultura. Observa, ainda, o modo como o conceito de competência aponta para processos de formação voltados à mera adaptação à lógica capitalista, reduzindo a vida ao trabalho.

PALAVRAS-CHAVE: Vida, Trabalho, Formação, Cultura, Capitalismo.

Abstract This paper questions the possibility of releasing the subjectivity, in the tension between life and work, which constitutes the professional qualification. It analyzes the similarities between training and work, towards a self-awareness and social consciousness in the context of culture. This study also notes how the concept of competence points to training processes aimed at mere adaptation to the capitalist logic, reducing life to work.

KEYWORDS: Life, Work, Training, Culture, Capitalism. 


\section{Introdução}

O processo de qualificação profissional é mediado pelas relações pouco coerentes e pouco controláveis entre vida e trabalho, quando observado do ponto de vista individual. Por outro lado, é objeto de políticas públicas ora mais ora menos articuladas, que visam a atender os interesses do capital.

Tais políticas envolvem, especialmente, reformas educacionais no sistema de ensino regular, propostas de ampliação do leque de oferta da educação permanente para o aprimoramento ou para maior flexibilização do trabalhador às necessidades do mercado e promessas de geração de empregos, lançadas não só pelos governos, mas também por meio de ações da sociedade civil organizada e por empresas.

Assim sendo, pode-se supor que a complexidade dos determinantes, que atuam no desenvolvimento desse processo impeça, pensá-lo, porque enreda a maioria das pessoas - sobretudo as que tem menos acesso e orientação para organizarem suas vidas - numa teia de questões que as deixam à mercê das crises e recuperações do capital. As crises são cada vez mais frequentes, as mudanças tecnológicas são cada vez mais velozes, os requisitos de qualificação e competências profissionais são cada vez mais ampliadas.

No âmbito da educação, ainda são fortes os quatro pilares do Relatório Jaques Delors para a UNESCO, publicado em 1996: aprender a conhecer, aprender a fazer, aprender a conviver e aprender a ser - mesmo que amplamente criticados pelo forte conteúdo adaptativo que carregam, implicando cada vez menos liberdade individual em favor de uma cultura afirmativa e, aparentemente, inexorável.

Poderia, então, o processo de qualificação profissional ser analisado, para além da necessidade mercadológica, como uma questão atravessada pelo campo de tensão vida/trabalho, podendo-se identificar, nesse campo de tensão, a fagulha que possibilita a libertação da subjetividade aprisionada pela cultura capitalista?

Buscando abordar essa questão, meu objetivo, neste artigo, é compreender o processo de qualificação, discutindo, principalmente, as aproximações entre a formação e o trabalho; bem como o desenvolvimento de uma interpretação para as relações que se estabelecem entre vida e trabalho em direção à consciência de si e à consciência social, na esfera da subjetividade possível pela cultura.

Nessa direção, minha abordagem considera as interações entre vida e trabalho, observando a reorganização do capital, que traz como consequências tanto novas exigências para o engajamento do indivíduo no mercado de trabalho, quanto novas dificuldades para sua inserção nesse mercado. Essas novas exigências se apresentam no debate sobre a constituição de competências. $O$ contexto exige reformas educacionais demandadas pelo mercado, mas também remete a discussão da possibilidade de uma formação humana para além da lógica do capital. 


\title{
Trabalho e subjetividade
}

O mercado formal divulga requisitos de qualificação que visam um dever ser do trabalhador, forjando um modelo, por meio de práticas de divisão e organização, que demandam maior envolvimento e participação. Embora tenda a absorver cada vez menos o contingente preparado, conforme suas necessidades anunciadas, as demandas divulgadas se alastram para além de todas as fronteiras.

Assiste-se a uma intensificação do trabalho de maneira mais sutil em direção a uma espécie de modelização da subjetividade, embrenhando-se no discurso de um poder compartilhado por equipes multifuncionais melhores preparadas e apontam para uma grande participação da qualificação tácita, que envolve aspectos da individualidade. Na esteira de novos métodos que mantém os princípios tayloristas sob nova roupagem técnica, a propaganda ideológica aponta que o trabalhador deve se tornar sujeito do processo de trabalho, elemento reforçado pela aplicação de técnicas voltadas à meritocracia.

Por outro lado, o modelo que inicia sua implantação na indústria de ponta - o núcleo duro da economia - avança para os demais setores, principalmente para as atividades de serviços. O discurso articulado por estratégias mercadológicas anunciam colocar a satisfação do cliente/consumidor no centro das preocupações empresariais, disseminando a crença de que esse cliente/consumidor é um indivíduo e que deve ser atendido de acordo com as suas peculiaridades. Assim, fomenta-se a idéia de que o indivíduo - como categoria social - está no centro dos interesses capitalistas, no tocante ao atendimento de suas necessidades, o que não deixa de ser verdadeiro quando se observa todo o empenho em torno da modelação da subjetividade, para adaptar-se às exigências do novo momento do capital, como observa Harvey (1996, p. 119):

\begin{abstract}
Asocializaçãodotrabalhadornascondições deproduçãocapitalista envolve o controle social bem amplo das capacidades físicas e mentais. A educação, o treinamento, a persuasão, a mobilização de certos sentimentos sociais (a ética do trabalho, a lealdade dos companheiros, o orgulho local ou nacional) e propensões psicológicas (a busca da identidade através do trabalho, a iniciativa individual ou a solidariedade social) desempenham um papel e estão claramente presentes na formação de ideologias dominantes cultivadas pelos meios de comunicação de massa, pelas instituições religiosas e educacionais, pelos vários setores do aparelho do Estado, e afirmadas pela simples articulação de sua experiência por parte dos que fazem o trabalho. Também aqui o "modo de regulação" se torna uma maneira sutil de conceituar o tratamento dado aos problemas da organização da força de trabalho para propósitos de acumulação do capital em épocas e lugares particulares.
\end{abstract}

Nesse movimento, se as próprias necessidades individuais e sociais vêm sendo historicamente (re)significadas e fetichizadas em favor do capital, qual o real significado dos discursos que colocam os interesses do indivíduo em seu centro? 
A polêmica, em torno do fim da centralidade do trabalho (representada por GORZ, 1987; SCHAFF, 1990; OFFE, 1990; entre outros), tem favorecido um foco de análise, que traz à tona a necessidade de rever as relações entre vida e trabalho, possibilitando que novas interpretações lancem mão da categoria indivíduocomofundamentalnacompreensãodastransformaçõescontemporâneas. Ao mesmo tempo, essas novas interpretações devem desempenhar um papel crítico que se apresente capaz de produzir uma ruptura com as grossas camadas interpretativas, que têm se enrijecido em torno das relações do indivíduo com o trabalho e com a própria subjetividade.

Segundo Gitahy (1994), o modelo de desenvolvimento emergente, que tem como mola propulsora a disseminação de novas tecnologias de base microeletrônica - as quais se desenvolvem exponencialmente, como vemos e consumimos cotidianamente - indica algumas questões quanto às implicações sociais, políticas e econômicas. Uma delas diz respeito à concepção de que os novos modelos produtivos apontam para um processo de reestruturação que deve priorizar as dimensões sociais, políticas e culturais, tendo em vista o aparente esgotamento do modelo tecnoeconômico (ou de organização industrial) de crescimento e de relações político-sociais. A outra centra-se na necessidade de se desenvolver um enfoque sobre a gênese e a história da produção social da ciência e da tecnologia, considerando que a microeletrônica, como carro-chefe das transformações contemporâneas, acentua a tendência de elevação contínua da base técnica do capital, alterando a divisão internacional do trabalho, sua divisão social e de gênero e, consequentemente, as relações sociais de produção e reprodução humana (estruturas familiares).

A capacidade de articular o sistema de inovações tecnológicas e organizacionais com a reorganização sociopolítica seria, então, um dos prérequisitos para o novo modelo de desenvolvimento. Mas, na esteira desse processo de articulação, há um complexo emaranhado de questões que encontram, muitas vezes, soluções improvisadas, cujas consequências vão se fazendo sentir na prática das negociações intersetoriais.

Vários estudos específicos apontam que, no caso brasileiro, as mudanças que vêm sendo introduzidas nas empresas (seja de forma pontual seja de forma sistêmica) implicam alterações substanciais nos modos de organização tradicionais que, em muitos casos, mostram-se incipientes e até contraditórios, em virtude da convivência de elementos do velho e do novo modelo (GITAHY, 1994, p. 144149).

O principal elemento do processo de mudança tem sido a implantação de Programas de Qualidade, iniciados e acompanhados, geralmente, com a ajuda de consultorias externas às empresas, visando á revisão de metas e objetivos, com reorganização orientada pelos princípios de um paradigma, que implica medidas como a redução dos níveis hierárquicos; a busca de cursos de capacitação dos mais diversos tipos; a mudança nas estruturas de remuneração; a introdução de um processo de qualificação de fornecedores, devido ao movimento de terceirização e 
às preocupações socioambientais; o aumento da importância atribuída à gestão de recursos humanos eàs políticas de treinamento e desenvolvimento, e a participação feminina no mercado de trabalho.

Esse movimento, que se iniciou na década de 1990, só tem feito ampliar-se. Por exemplo, a estratégia de terceirização parece ter-se consolidado como elemento importante para o enxugamento das empresas, acentuando-se com os momentos de crise econômica, as pressões por redução de custos e aumento da produtividade e da competitividade, tanto quanto como solução para a demanda por trabalho.

Esse movimento de externalização das atividades, em busca de maior competitividade, indica duas diferentes trajetórias - uma, representada pelo esforço articulado entre a grande e a pequena empresa, no sentido de qualificar fornecedores e melhorar a qualidade dos produtos e serviços; a outra, representada pela tentativa de redução de custos (tornando precárias as condições de emprego e comprometendo a qualidade dos serviços prestados) - leva à criação de redes de subcontratação e a novas formas de relação entre as empresas, bem como entre empresas e trabalhadores, marcadas pela heterogeneidade, pela flexibilização dos contratos e pela precarização do trabalho dos menos qualificados, de modo que não se contribui para que haja uma melhora dos níveis educacionais.

Esse quadro traz nova centralidade à educação como solução para os problemas de formação de mão de obra qualificada, mas, ao mesmo tempo, torna difícil identificar que mudanças se operam, objetivamente, em relação ao conteúdo das qualificações, uma vez que os novos requisitos apontam, especialmente, para qualificações tácitas, como prioritárias para absorver e integrar as dimensões do novo paradigma de desenvolvimento. Para muitas pessoas, essas qualificações tácitas representam apenas e tão somente obediência e submissão à normas e padrões de comportamento. Não raro, observa-se em diversas empresas que os funcionários de empresas terceirizadas - geralmente, pessoal de limpeza e segurança - são tratados pelo nome das empresas, reconhecidos por uniformes que pasteurizam e camuflam sua identidade - aliás, pode-se dizer, uma identidade negada. Mas esse processo não ocorre de forma idêntica em todos os níveis.

\section{Competência como conceito central no trabalho}

As chamadas qualificações tácitas se formam pela experiência subjetiva ou por uma forma de conhecimento, que está na base da constituição da experiência de qualificação, adquirida por tempo de atividade num ou mais postos de trabalho.

Se essa experiência de qualificação é insubstituível, apesar das inovações técnicas (ainda incapazes de internalizar experiência, vivência e memória do trabalhador individual), as qualificações tácitas guardam a ideia de que"a qualificação do trabalhador vai passando por transformações que expressam concepções diferenciadas de homem". (KUENZER, 1992, p. 54) 
Por outro lado, por necessitar desenvolver entre seus colaboradores a iniciativa, a atividade cognitiva, a capacidade de raciocínio lógico e o potencial de criação, para possibilitar respostas imediatas, a empresa pós-fordista, ao mesmo tempo que concede algum grau de autonomia, constrói situações que levam os indivíduos a incorporar regras de funcionamento da companhia como elementos de sua percepção, gerando uma espécie de reordenamento da subjetividade, para garantir a efetividade dessas regras, como analisou Heloani (1994).

A substituição de ordens por regras, nesse processo, sofistica os enunciados do poder, cujo objetivo está na imposição de um quadro de referências a ser absorvido como um conjunto de valores que identificam o indivíduo com a empresa, garantindo a adesão, não apenas aos objetivos formulados, mas à habilidade de alterá-los em função de resultados desejáveis. O requisito da flexibilidade favorece, amplamente, o desenvolvimento dessas regras, que se legitimam por meio da linguagem.

Pagès (1978) entende que essa utilização da linguagem fornecerá os princípios orientadores das ações dos indivíduos, dentro da empresa, e a identificação com os valores da empresa reafirma e legitima o poder detido por aqueles que formulam as regras, gerando uma apropriação das relações pessoais e sociais em função da produtividade, da competitividade e do lucro - processo que o autor denomina gestão do inconsciente ou gestão da subjetividade.

Esse processo de gestão leva o indivíduo a uma fusão afetiva com a empresa que reproduz aquilo que o autor chama de paradigma maternal. Ela oferece vantagens como promoções, benefícios, salários elevados, distinções (como sala própria, elevador especial, crachá, prêmios, etc) e deve ser retribuída com a fidelidade e com uma constante capacidade de adaptação e de entrega, como discute Dutra (2008).

Além disso, esse paradigma é reforçado pela intensificação do trabalho, com o aumento da angústia, provocada pelas exigências sobre o desempenho do indivíduo, que passa a incorporar novas tarefas (aparentemente atraentes), que exigem criatividade, em alguns casos, novas responsabilidades e aumento das competências sociotécnicas - típicas da qualificação tácita - que vão sendo incorporadas pelas novas gramáticas do poder.

A utilização dessas novas gramáticas sobre o saber tácito permitem maior e melhor apropriação do trabalho, no sentido do disciplinamento da percepção, para novas funções e, ao mesmo tempo, têm afinidade com o obscurecimento da intensificação do trabalho. São especialmente os jovens bem formados os que se encontram no foco central dessas estratégias de gestão do capital humano.

Nesse sentido, os funcionários tendem a ficarem absorvidos pela imediatez, e não conseguem fazer uma leitura mais ampla do contexto e da cultura das organizações em que atuam, encontrando seu espaço ocupacional e desenvolvendo suas competências de forma autônoma, como descreve Dutra (2008). Todo um sistema de regras, benefícios, avaliações, treinamentos e até 
mesmo o coaching (como prática de desenvolvimento subjetivo do profissional) são utilizados para levar o indivíduo à adaptação.

É possível observar, então, que a empresa procura identificar-se, em inúmeros aspectos, com a estrutura da família. Ela incorpora elementos que estão presentes na convivência familiar e, principalmente, no papel da mãe, para conduzir os indivíduos à adaptação e à integração.

Para Habermas (1983), à medida que avança, o progresso científico e técnico penetra as instituições sociais, revelando a racionalização' legitimada pelo industrialismo e o comportamento humano, mesmo atrelado à gramática dos jogos de linguagem, que conduz à interiorização de determinadas normas, não impede a reflexão, o que possibilitaria uma descompressão no domínio comunicativo. Dessa forma, se constituiria uma nova racionalização que "ofereceria aos membros da sociedade as chances de uma emancipação mais ampla e de uma individuação progressiva" (p. 341). Além disso, "o crescimento das forças produtivas não coincide com a intenção do 'bem viver' mas pode, em todo caso, ser útil a essa intenção". A esfera da interação humana seria propícia para a liberdade e a socialização que, nesse âmbito, se daria por incorporação de regras, em contraste com a esfera do trabalho, na qual o conhecimento efetivo seria rígido e o saber não poderia ser relativizado. $O$ problema é que a racionalidade do mundo do trabalho invade a esfera da interação humana, aprisionando-a em sua lógica.

Uma reflexão propiciada por essas diferentes análises pode sugerir que os novos métodos de organização do trabalho e as competências por eles demandadas escondem uma nova forma de ideologia sob a aparência de liberdade e autonomia do sujeito.

Ao mesmo tempo, a reorganização do sistema educacional volta-se a uma artificial ressonância entre o espaço familiar, o escolar e o de trabalho, como se fossem todos continuidade de um mesmo processo social, no qual o indivíduo se desenvolve, com o qual deve identificar-se e ao qual deve adaptar-se. As estruturas familiares se ampliam, assim como as tarefas da instituição escola. As fronteiras entre as instituições tornam-se cada vez mais fluidas.

Um grande número de pesquisadores (DADOY, 1984; KERGOAT, 1984; PARADEISE, 1987; DUBAR, 1987; ROLLE, 1989; e DUGUÉ, 1994; entre outros) entende que as preocupações que se têm, hoje, sobre a qualificação são as mesmas de 40 anos atrás. Portanto, há uma tendência dominante a entendê-la como uma construção histórica e social, de natureza tácita (DADOY, 1994, p. 5682).

Embora se possa concordar com essa abordagem, é preciso questionar a forma como tem se dado a discussão da sociologia do trabalho em torno da qualificação profissional. Trata-se de uma discussão de caráter predominantemente adaptativo, que não aloja a perspectiva crítica acerca de como o indivíduo vem sendo modelado de modo a manter a negação da sua subjetividade. Em geral, os estudos apontam para uma leitura descritiva das relações entre capital e 
trabalho, recheadas de interpretações simplistas, que acabam indicando, apenas, a integração do indivíduo e sua adaptação para a manutenção dos processos de dominação, como poderá ser constatado adiante.

Rolle (1989, p. 83-87) reconhece que, à medida que se modifica a divisão social do trabalho e, a partir de um novo modelo para sua organização, esse conceito tende a alterar-se, em função das novas exigências do posto de trabalho, em que a colaboração, o engajamento, a mobilidade, passam a ser as qualidades dominantes num estado instável de distribuição de tarefas, que mobilizam, reproduzem e adicionam diversas formas de trabalho. Assim, a qualificação "... existe como conjunto das normas que as organizações profissionais ou políticas impõem, em um dado momento, na vida do trabalho."

Dugué (1994, p. 73-292) esclarece que, a noção de qualificação é referida à noção de postos de trabalho, típica da organização de trabalho taylorista; com a mudança desse paradigma, surge a noção de competência, relativa às novas formas de organização do trabalho, fundadas sobre a valorização da implicação subjetiva da consciência, amplamente associada à noção de transferibilidade, favorecendo a elaboração de espaços profissionais que permitam a flexibilidade, o que demandaria que as pesquisas sobre a qualificação fossem abraçadas por áreas como psicologia e psicossociologia.

Essa afirmativa provoca a indagação: a perspectiva da autora revelaria a intenção de que, a participação da psicologia e da psicossociologia devessem apontar para a possibilidade da crítica ou para a compreensão sobre como se forjam os esquemas integrativos e adaptativos do trabalhador?

A resposta certamente apontaria para vertentes diferentes no plano da superação ou da manutenção da dominação social, pois uma análise que implique a participação da sociologia e da psicologia - como o faz a teoria crítica da sociedade - leva em conta que ambas as áreas de conhecimento não podem ser integradas nem vistas como complementares:

A separação entre Sociologia e Psicologia é verdadeira e falsa ao mesmo tempo. Incorreta enquanto aceita como se fosse recibo da renúncia ao conhecimento da totalidade que ordenou essa separação; correta na medida em que registra a ruptura cumprida na realidade como demasiado irreconciliável para uma precipitada unificação conceitual. (ADORNO, 1991, p. 159-160)

Ambas as disciplinas têm preocupações e objetivos diferentes: à sociologia interessam as formas de conduta e atitudes do indivíduo, que sejam, relevantes para o sistema social, enquanto a psicologia vê o indivíduo de forma isolada, abstrata, sem enxergar como este se produz socialmente. Numa sociedade antagônica, os indivíduos não se reconhecem como sujeitos, mas são forçados a identificar-se aos demais; por isso, se indivíduo e sociedade não se reconhecem um no outro, embora não existam um sem o outro, psicologia e sociologia não podem ser integradas, ainda que suas análises sejam sempre parciais, quando consideradas isoladamente. 
Assim, é preciso que essa abordagem esclareça o que significa terem sido os estudos sobre a qualificação abraçados por uma psicossociologia. Se for para encontrar os meios de integrar e adaptar os indivíduos com maior eficiência à lógica do mercado, esse estudo se faz dispensável, porque essa lógica já contém suficientes elementos para negar ao indivíduo a autorreflexão, a experiência e a subjetividade. Se for para denunciar o quanto os processos de qualificação e desenvolvimento de competências socioprofissionais têm negado ao indivíduo manifestar a subjetividade e apontar-lhe o caminho da auto-reflexão, psicologia e sociologia não precisam ser integradas, apenas a psicologia não deve se negar a reconhecer que o indivíduo não surge fora das relações sociais, enquanto a sociologia deve ter presente que o universal permite a existência do particular e que a subjetividade não destrói, necessariamente, a objetividade:

\begin{abstract}
...a antítese entre universal e particular é tão necessária quanto falaz. Nenhum dos dois existe sem o outro; o particular só existe como determinado e, nesta medida, é universal; o universal só existe como determinação do particular e, nesta medida, é particular. Ambos são e não são. Este é um dos motivos mais fortes de uma dialética não-idealista. (ADORNO, 1995b, p. 199)
\end{abstract}

Isso significa que, não há como harmonizar as relações entre psicologia e sociologia, tanto quanto as relações entre sujeito e objeto, sobretudo porque reside, em suas diferenças, a fertilidade da crítica que pode revelar as contradições existentes entre conceitos, que se encontram mediados reciprocamente, resgatando a possibilidade da autorreflexão. Hirata $(1992$, p. 6) remete sua análise à passagem das teses sobre a polarização das qualificações para o modelo de competência, apontando que tal modelo distinguiria a qualificação formal da qualificação tácita, no contexto das mudanças tecnológicas e organizacionais, que configuram o novo paradigma produtivo, em substituição ao modelo taylorista-fordista (embora essa distinção já existisse sob o fordismo).

Há uma polêmica em torno da substituição do conceito de qualificação pelo conceito de competência, que está apoiada em falsos pressupostos. O que parece emergir dessa discussão é o quanto ambos os conceitos escamoteiam a dinâmica, que se realiza entre as forças produtivas e as relações de produção. Todos os aspectos, que têm sido postos em evidência para o estudo da qualificação, tanto quanto os que vêm sendo enumerados em relação à compreensão da competência, não têm servido para apontar formas de superação das relações de dominação que estão dadas no mundo do trabalho. Num e noutro conceito, permanecem intocadas as bases da dominação por meio de estratégias da divisão social e das técnicas de organização do trabalho, cujos princípios permanecem inalterados.

Se, no início da revolução industrial, era requerido um trabalhador obediente e integrado que pusesse à disposição da empresa a sua força física e um mínimo de habilidades para a execução eficiente de tarefas, a sociedade contemporânea continua requerendo um trabalhador obediente, ainda que the exija a capacidade de pensar, criar, desenvolver iniciativa para resolver problemas 
e outros requisitos tácitos. Esses requisitos voltam-se à manutenção da lógica do trabalho alienado e não à lógica da emancipação e da liberdade.

Kergoat (1984, p. 26-29) já salientou dois níveis de abordagem à questão da qualificação: um diz respeito à qualificação do emprego, outro à qualificação dos trabalhadores. O primeiro envolve um conjunto complexo de requisitos ,classificados por meio dos postos de trabalho e das diferenciações salariais, definidos pela empresa - que legitimam a divisão do trabalho por meio das políticas de gestão de pessoas e do grau de incorporação de tecnologia. O segundo, referindo-se à qualificação do trabalhador, envolve sua formação e experiência, incorporando qualificações (ou competências) sociais ou tácitas.

Segundoaautora, a aquisição dehabilidadesamplamenterequeridaspelo mercado de trabalho, por meio de canais institucionais de qualificação, pertence à esfera privada, por tratar-se de uma aquisição individual e não coletiva. $\mathrm{O}$ aspecto coletivo só aparece na relação social, quando os trabalhadores se mobilizam no sentido de valorizar seus conhecimentos profissionais, por meio de negociações que alterem a qualificação do emprego, definida pela empresa. Tal movimento entre as forças capital/trabalho realiza a qualificação como relação social, que é onde se daria a interferência ou participação do sujeito, da subjetividade e das relações intersubjetivas, que condicionam o sucesso da implantação dos novos paradigmas organizacionais, apoiados na comunicação. Pode-se pensar que este movimento, antes feito por meio dos sindicatos, tem perdido, cada vez mais, a sua força. Nesse sentido, os trabalhadores são cada vez menos organizados (ainda que os sindicatos sobrevivam às custas de suas contribuições).

Na sociedade industrial, o trabalhador permanecia num espaço fechado, executando suas tarefas de modo a adequar-se ao ritmo da máquina, na esfera da produção. Na sociedade contemporânea, o trabalhador continua tendo que adequar-se à lógica da máquina, entretanto já não se encontra confinado ao espaço da produção: movimenta-se na distribuição dos produtos e serviços que dela decorrem e de outros serviços que a sociedade de consumo vai gerando. Isso faz com que se amplie o espaço de relações, mas essas relações também devem obedecer a determinados critérios que moldam o trabalhador. É o que permite questionar a existência de uma real possibilidade de interferência e participação do sujeito, da subjetividade e das relações intersubjetivas.

Se, antes, o trabalhador ficava confinado ao espaço da fábrica e não precisava saber comunicar-se ou vestir-se bem, hoje, a venda dos produtos se relaciona à venda de sua própria imagem como extensão da imagem da empresa e do produto que ela coloca no mercado. Ele precisa apresentar-se de modo que não deprecie o produto, comunicar-se de modo a valorizá-lo e resolver os problemas que possam impedir seu consumo - mesmo que não consiga comunicar-se bem.

A honestidade, o caráter, a criatividade, a boa comunicação, a iniciativa, a boa aparência, o empreendedorismo, a liderança são características da imagem que, a empresa quer que estejam associadas aos seus produtos, como estratégias mercadológicas, mas também a obediência e a submissão a determinados padrões. 
Portanto, os trabalhadores devem incorporar essas características ao seu modo de ser e fazer; não apenas para vender os produtos, mas também para consumí-los. Ao tornar-se extensão da empresa e incorporar as características voltadas às estratégias mercadológicas de distribuição dos produtos, o trabalhador torna-se parte do produto, torna-se mercadoria. Sendo assim, revela-se o engodo da possibilidade que as chamadas novas técnicas de organização do trabalho abririam ao trabalhador no sentido de sua interferência e participação. Estas já estão, de antemão, moldadas, portanto não se referem a uma subjetividade livre, mas à sua negação.

Paradeise (1987, p. 35-46) constata que a mudança nos processos de produção, sempre, afeta os trabalhadores preparados para o processo anterior, desqualificando-os ou obrigando-os a acompanhar a evolução dos novos requisitos de qualificação. Portanto, a matriz profissional é formada pela articulação dos saberes formais, requeridos pelo mercado, e os saberes informais, adquiridos no posto de trabalho. Por essa razão, cabe aos sistemas de remuneração contribuir para uma regulação (mais ou menos harmoniosa, mais ou menos caótica), dos mercados de trabalho. Isso atribui uma dupla função aos processos sociais de aprendizagem e acesso aos postos de trabalho: regulação das competências e regulação das remunerações. Ainda que o argumento soe exagerado, há de se considerar que a própria menção à regulação mais ou menos harmoniosa, mais ou menos caótica do mercado de trabalho pelos sistemas de remuneração, já aponta para uma suposta aceitação do fato de o indivíduo ter-se tornado mercadoria.

Além disso, a regulação das competências e a regulação dos sistemas de remuneração têm-se apresentado, sob o signo do desemprego estrutural, por meio de formas altamente coercitivas. A mídia se encarrega de demonstrar o padrão de comportamentos e atitudes que devem ser incorporados e de disseminar quais são os requisitos de qualificação que devem ser perseguidos pelos trabalhadores. A ameaça de desemprego mantém os salários dos empregados em baixa, enquanto seu trabalho é intensificado e as empresas investem na automação da produção. Os desempregados, por sua vez, dedicam-se à incorporação dos padrões ditados pelos meios de comunicação e vão buscando formas alternativas de subsistência, na expectativa de serem reabsorvidos pelo mercado de trabalho, uma vez que dêem conta das demandas de competências, habilidades, atitudes e valores. Conceitos como o de empregabilidade servem bem a esse propósito. Manter-se empregável é sempre um desafio à sobrevivência do indivíduo.

A única alternativa apresentada ao indivíduo é adaptar-se às exigências do mercado, ainda que as estatísticas apontem que a riqueza acumulada já pudesse dar conta de erradicar a miséria e manter um bom padrão de sobrevivência a todos os indivíduos. O que se mantém, então, sob a égide dessa racionalidade contábil, é a irracionalidade completa no sistema totalitário do mundo administrado, cuja propaganda prega o suave funcionamento do todo, sob as benesses da tecnologia.

Dubar (1987, p. 3-14) interpreta os recentes debates, verificando que as análises sobre a questão da qualificação têm tendido a envolver a distinção entre qualidades subjetivas e saberes objetivos. As qualidades subjetivas se 
realizariam por meio da competência, como qualidades profissionais construídas a partir da experiência e da personalidade (o trabalho profissional como arte). Em contrapartida, há uma qualificação jurídica (a profissionalização como ciência), tradicionalmente associada à instrução e à transmissão de saberes disciplinares. O exercício de uma profissão suporia, portanto, uma articulação entre esses dois conceitos, o de competência e o de qualificação júridica.

Nesse sentido, a qualificação envolve um corpo de saberes interiorizados e um saber-fazer objetivo, que têm por base uma formação escolar, garantida pela experiência social e incorporada por esquemas profissionais. Segundo o autor, tal pressuposto tem colocado as investigações sobre o tema, como que oscilando entre dois extremos, difíceis de conciliar (como é possível perceber, também, por meio desta resenha de alguns dos estudos mais significativos produzidos pela sociologia do trabalho). De um lado, estudos analíticos, centrados no indivíduo em relação aos saberes que são mobilizados em função de formações anteriores e de experiências profissionais; de outro, investigações globais, sintéticas, orientadas para a organização e gestão de recursos humanos.

Dubar propõe, então, que se busque uma articulação totalizante entre esses extremos, a partir da biografia do indivíduo, sua trajetória específica e as interações sociais, considerando uma totalização estrutural, a partir do, conhecimento dos campos de atuação profissional e da articulação dos sistemas educacional e ocupacional, para a reconstrução de coerências globais, provocando em direção e sugerindo a conveniência da análise da trajetória biográfica no processo de qualificação e trabalho.

Por outro lado, os dois extremos apresentados enfatizam a submissão do trabalho ao capital: a lógica do mercado, a adaptação do indivíduo a essa lógica, a adequação dos sistemas de educação formal e de (re)qualificação, a disposição dos saberes formais e informais dos trabalhadores (em todos os níveis) para atender às necessidades da produção, a incorporação dos conteúdos das experiências do trabalhador pela empresa, a identificação do trabalhador com os valores e princípios empresariais.

Como anunciado, esta síntese demonstra que a discussão da sociologia do trabalho em torno da qualificação e das competências socioprofissionais é uma discussão de caráter predominantemente adaptativo, que não aloja a perspectiva crítica acerca de como o indivíduo vem sendo modelado, de modo a manter a negação da sua subjetividade. As referências tomadas apontam apenas para a integração do indivíduo e para a manutenção dos processos de dominação, como já foi constatado e repetido em várias oportunidades, ao longo dessa discussão.

\section{Para completar: os sistemas de formação numa lógica perversa de dominação social}

Nesse movimento das relações entre capital e trabalho pode-se ver que os sistemas de formação estão a serviço do capital, incluindo todas as suas 
contradições. Se organizados em políticas bem articuladas não se sustentam por muito tempo. Sempre faltam dados, informações, elementos estruturantes que possibilitem avanços efetivos na base da formação, de forma a preparar as pessoas para a vida social, que inclui o trabalho.

Inúmeras pesquisas apontam a importância de uma educação de qualidade, para uma boa preparação, para o trabalho, e para a subsistência material. Bilhões são gastos para corrigir ou para lidar com os efeitos nocivos de pessoas mal formadas, que desconhecem determinadas regras de higiene, que convivem em lugares insalubres, que não preparam adequadamente os alimentos e não conhecem boas práticas alimentares, só para citar alguns exemplos cotidianos.

Entre inumeráveis contradições, há muitas pessoas, nos próprios meios acadêmicos e políticos, que não entendem a necessidade e o significado das creches como direito das crianças e suas mães, sobretudo quando envolvem populações em vulnerabilidade e risco social. Há pessoas que não entendem o investimento obrigatório de $25 \%$ do orçamento de estados e municípios para a educação básica. Há pessoas que estão envolvidas com a alfabetização de crianças, mas não se responsabilizam efetivamente por alfabetizá-las. São questões ligadas ao desenvolvimento de uma educação que prepare para a vida social.

Deoutra parte, enquanto nos dedicamos à crítica ao dualismo na formação profissional, ainda não temos, no país, um sistema de pesquisa e planejamento da formação profissional para vários níveis, que dê conta das próprias necessidades de mão de obra qualificada, desde a mais simples à mais sofisticada. Os casos extremos estão presentes nas piores atividades, como ajudante geral e pedreiro ou empregada doméstica, de um lado, enquanto de outro, faltam engenheiros e profissionais preparados para o desenvolvimento e utilização de alta tecnologia, por isso o país importa esses profissionais ${ }^{2}$, aumentando consideravelmente a quantidade de vistos de trabalho concedidos a estrangeiros, nos últimos anos ${ }^{3}$. Buscam-se profissionais para abastecer o mercado de trabalho, mas não se busca desenvolver um sistema de formação eficiente para o próprio brasileiro. Com isso, mantemos a minoridade social e a dominação da pior espécie.

Já há inúmeros estudos do IPEA (Instituto de Pesquisa Econômica Aplicada) demonstrando o quanto a falta de mão de obra qualificada, em vários níveis, tem sido danosa para o crescimento econômico e para o desenvolvimento social do país, mas não conseguimos enfrentar esse problema. Por que? Fenômenos ligados à questão multiplicam-se, numa complexidade multifacetada, que tendem a levar às pesquisas perspectivas muito pontuais. Não raro, se toma um aspecto de um dado fenômeno em profundidade, mas se perde em abrangência. Ou se busca abrangência sem se conseguir aprofundamento de análise. No enfrentamento dessa contradição, uma hipótese a ser testada à exaustão e ligada à nossa constituição como povo, apesar da característica pasteurizante e totalitária do capitalismo, é que mantemos a cultura do colonialismo e da dominação social, a tal ponto, que esses elementos tendem a voltar-se cada vez mais contra nosso progresso como povo. Assim, aponta-se um crescimento econômico sempre 
limitado por um desenvolvimento social restrito a supostas ilhas de excelência. Assim, a subjetividade mantém-se negada, a individualidade limitada à capacidade de adaptação e às possibilidades de consumo decorrentes da manutenção da empregabilidade. É preciso enfrentar o tabu dessa cultura instalada para que se possa superá-lo.

\section{Referências}

ADORNO, T. W. Capitalismo Tardio ou Sociedade Industrial? In: COHN, G. (Org.). Theodor W. Adorno. São Paulo: Ática, 1986. Vozes, 1995 a.

Notas Marginais sobre Teoria e Práxis. Palavras e sinais: modelos críticos 2. Petrópolis: Sujeito e Objeto. Palavras e sinais: modelos críticos 2. Petrópolis: Vozes, $1995 \mathrm{~b}$.

ADORNO, T. De la relacion entre sociologia y psicologia. Actualidad de la Filosofia. Pensamiento Contemporáneo, n. 18, Barcelona: Paidós. 1991.

BAETHGE, M. Trabalho, socialização, identidade - a crescente subjetivação normativa do trabalho. MARKET, W. (Org.). Teorias da Educação do Iluminismo, conceitos de trabalho e do sujeito. São Paulo: Tempo Brasileiro. 1994.

DELORS, J. et al.. Educação um tesouro a descobrir: Relatório para a UNESCO da Comissão Internacional sobre Educação para o século XXI. Brasília: Unesco: 1996

DADOY, M. Qualification et structures sociales. CADRES. n. 313, Paris: CFDT, 1984.

DUBAR, C. La qualification à travers les Journées de Nantes. Sociologie du Travail, Paris: $n$. 1,1987

DUGUÉ, É La gestion des compétences: les savoirs dévalués, le pouvoir occulté. Sociologie du travail, Paris: n. 3, 1994.

DUTRA, J. Competências: conceitos e instrumentos para a gestão de pessoas na empresa moderna. São Paulo: Atlas, 2008.

GITAHY, L. Inovação Tecnológica, Subcontratação e Mercado de trabalho. Revista São Paulo em Perspectiva. São Paulo: Fundação SEADE, v. 8, n. 1, 1994.

GORZ, A. Adeus ao proletariado para além do socialismo. Rio de Janeiro: Forenseuniversitária. 1987.

HABERMAS, J. Técnica e Ciência Enquanto Ideologia. Os Pensadores. São Paulo: Abril, 1983.

HARVEY, D. Condição Pós-moderna. São Paulo: Edições Loyola, 1996.

HELOANI, R. Organização do trabalho e administração: uma visão multidisciplinar. São Paulo: Cortez, 1994.

HIRATA, H. Da Polarização das Qualificações ao Modelo de Competência: a Evolução do Debate no Contexto dos novos paradigmas de Organização Industrial. Workshop Trabalho e Educação. ANPED. 44a. Reunião Anual da SBPC, 1992.

KERGOAT, D. Masculin/Feminin: division sexuelle du travail et qualification. CADRES, CFTD, Paris, n. 313, 1984.

KUENZER, A. Z.. Humanismo e Tecnologia numa Perspectiva de Qualificação Profissional. Revista Tecnologia Educacional, São Paulo, v. 21, p. 107,1992.

MARCUSE, H. A. Ideologia da Sociedade Industrial. Rio de Janeiro: Zahar. 1969. 
MARCUSE, H. A. Sobre o caráter afirmativo da cultura. Cultura e Sociedade. São Paulo: Paz e Terra, 1997, v. I.

MARX, K. O Capital. São Paulo: Diefel, 1982, Livro 1, v. I.

OFFE, C. Sistema Educacional, Sistema Ocupacional e Políticas de Educação: contribuição à determinação das funções sociais do sistema educacional. Educação e Sociedade. n. 35, São Paulo: Cortez Editores. 1990.

. Trabalho e sociedade: problemas estruturais e perspectivas para o futuro da sociedade do trabalho. v. I e II. Rio de Janeiro: Tempo Brasileiro. 1991.

. Capitalismo Desorganizado. São Paulo: Brasiliense, 1995.

PAGÈS, M. et al.. O poder das organizações: a dominação das multinacionais sobre os indivíduos. São Paulo: Atlas, 1978.

PARADEISE, C. Des savoirs aux compétences: qualification et régulation des marchés du travail. Sociologie du travail. Paris. 1987. n. 1.

PIOTET, F. Qualification et Culture. CADRES, CFDT: Paris, 1984, n. 313.

RICARDO, D. Princípios de economia política e tributação. cap. I, seções I a VII. Coleção Os Pensadores. São Paulo: Abril, 1974.

RIFKIN. J. O fim dos empregos: o declínio inevitável dos níveis dos empregos e a redução da força global de trabalho. São Paulo: Makron Books, 1996.

ROGGERO, R. Revolução microinformática no setor terciário: impactos e tendências para a qualificação e para a Educação. (Mestrado em Educação) Programa de Estudos Pós-Graduados em Educação: História e Filosofia da Pontifícia Universidade Católica de São Paulo, 1996.

ROGGERO, R.; RODRIGUES, T. T. O resgate da subjetividade: processos de qualificação profissional frente às novas tecnologias de informação. (Monografia em Administração de Recursos Humanos) Centro de Aperfeiçoamento Profissional da Fundação Armando Âlvares Penteado, de São Paulo, 1997.

ROLLE, P. O que é a qualificação do Trabalho? In: HIRATA, H. (Org.). Divisão capitalista do trabalho, Tempo Social. São Paulo: USP. 1989.

SCHAFF, A. Sociedade Informática. São Paulo: Unesp, 1990.

SMITH, A. Investigação sobre a natureza e as causas da riqueza das nações. Coleção Os Pensadores. São Paulo: Abril, 1974.

\section{Notas}

\footnotetext{
'Segundo Habermas (1973, p.313), racionalização significa "ampliação dos setores sociais submetidos a padrões de decisão racional. A isso corresponde a industrialização do trabalho social, com a conseqüência de que os padrões de ação instrumental penetram também em outros domínios da vida (urbanização dos modos de viver, tecnicização dos transportes e da comunicação)" - aspectos bastante presentes na vida contemporânea.

${ }^{2} \mathrm{O}$ caso mais recente tem sido o da importação de médicos, conforme proposto pelo Ministério da Saúde (2013), mas já há quem fale do mesmo tipo de solução para a falta de professores em todos os níveis.

${ }^{3} \mathrm{O}$ Jornal Valor Econômico apontou com grande frequência esse fenômeno ao logo de todo o ano de 2012. Várias matérias apontaram para a concessão de uma média de 1700 vistos de trabalho por mês, no Brasil.
} 
Rosemary Roggero

* Professora Doutora da Universidade Nove de Julho, Programa de Pós-Graduação em Educação (PPGE). Sao Paulo, São Paulo - Brasil.

\section{Correspondência}

Rosemary Roggero - Universidade Nove de Julho, Programa de Pós-Graduação em Educação (PPGE).

Av. Francisco Matarazzo, 612, Agua Branca, CEP: 05001-100 - Sao Paulo, São Paulo - Brasil.

E-mail: roseroggero@uol.com.br

Recebido em 25 de maio de 2013

Aprovado em 12 de julho de 2013 